\title{
WEAR OF HUMAN ENAMEL OPPOSING ULTRA- TRANSLUCENT ZIRCONIA WITH TWO SURFACE FINISHING PROCEDURES
}

\author{
Salma A. Emam ${ }^{1}{ }_{B D s}$, Samir A. Koheil2 Ph.D,Rania R. Afif 3 Ph.D
}

\begin{abstract}
INTRODUCTION: With the advancement of material technology, CAD-CAM zirconia restorations have become increasingly popular. Their influence on the opposing tooth surface wear requires further investigation to ensure clinical occlusal stability.

OBJECTIVES: to determine wear behavior and surface roughness of enamel when opposed by ultra-translucent monolithic zirconia (UTMZ) with two surface finishing procedures (glazed or polished).

MATERIALS AND METHODS: This in vitro study consisted of three groups; Group A: enamel opposing glazed ultra-translucent zirconia, Group B: enamel opposing polished ultra-translucent zirconia, and Group C: enamel opposing enamel as a control group. A modified custommade tooth brushing machine was used for chewing simulation. The zirconia specimens and the enamel antagonists were subjected to 120,000 cycles with vertical load 49N. The amount of wear was determined based on percentage of weight loss. Qualitative and quantitative analysis of the specimens' surfaces ware carried out using 3D laser scanning microscope. Data were analyzed with a 1-way ANOVA and Games-Howell post hoc tests $(\alpha=0.05)$

RESULTS: Enamel surface wear was significantly affected by the opposing surface after chewing simulation, with antagonist natural enamel causing the greatest wear and polished UTMZ the least.

There was a significant increase in the surface roughness of both the zirconia specimens and the enamel antagonists after wear test.

CONCLUSION: Within the limitations of this study, polished UTMZ was shown to be more wear friendly to the antagonist enamel than both the glazed UTMZ and natural enamel. Increase in the surface roughness leads to an increase in the amount of antagonist wear.

KEYWORDS: Enamel wear, ultra-translucent, zirconia, surface roughness.

RUNNING TITLE: Wear of human enamel opposing ultra-translucent zirconia
\end{abstract}

1 Instructor of Restorative Dentistry, Conservative Dentistry Department, Faculty of Dentistry, Alexandria University, Alexandria, Egypt.

2 Professor of Conservative Dentistry, Department of Conservative Dentistry, Faculty of Dentistry, Alexandria University, Alexandria, Egypt.

3 Lecturer of Conservative Dentistry, Department of Conservative Dentistry, Faculty of Dentistry, Alexandria University, Alexandria, Egypt.

*Corresponding author:

E-mail: salma.emam@dent.alex.edu.eg

\section{INTRODUCTION}

Zirconia has become an increasingly popular restorative material due to its biocompatibility, and excellent mechanical and physical properties (1). Despite these advantages, zirconia has a major drawback, which is its opaque white color that lacks translucency which necessitates veneering of the zirconium core with a more translucent ceramic material to achieve better esthetics and more natural appearance (2). However, chipping and delamination of the veneering ceramic occurs frequently with the zirconium core (3). To overcome this problem, full contour monolithic translucent zirconia could be an alternative approach for the traditional zirconia restorations. The full contour monolithic zirconia is supposed to withstand high occlusal loads in minimal thickness of $0.5 \mathrm{~mm}$. This major clinical advantage of the monolithic zirconia that it requires less natural tooth reduction compared to that of the veneered crowns (4). Ultra-translucent monolithic zirconia (UTMZ) was recently introduced and claimed to possess an enhanced translucency similar to that of the lithium disilicate (5).

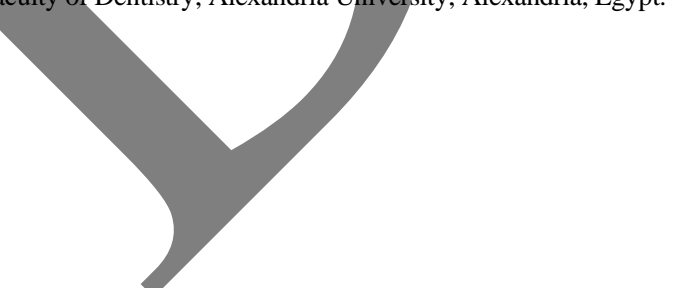

This makes it a highly versatile product to be used in the esthetic zone.

Wear is defined as the loss of restorative material and/or its antagonist surface because of mechanical contact with a solid or liquid body (6). When the enamel surface is subjected to occlusal wear, non-carious surface tooth loss develops leading to subsequent changes in the tooth anatomy (7). Excessive wear of teeth and the opposing restorative material can lead to occlusal instability, decrease in the vertical dimension, masticatory malfunction, esthetic problems, and disharmony of the stomatognathic system (8).

Tooth wear is a complex multi-factorial process. It is strongly influenced by the type of the opposing restorative material, its fracture toughness, the occlusal load, its surface roughness, and lubrication (9). Ideally, the restorative material should have similar wear properties to that of the human enamel (7). Even though monolithic zirconia restorations could be a reliable alternative to the traditional veneered zirconia, their abrasiveness against enamel antagonists and the subsequent enamel wear is still a clinical concern. Therefore, the aim of 
this study is to investigate the effect of the surface finish of UTMZ (glazed or polished) on the antagonist enamel wear and surface roughness. The null hypotheses were that the finishing procedure of the UTMZ will not affect the antagonist enamel wear and surface roughness in comparison to natural opposing enamel.

\section{MATERIALS AND METHOUDS}

The minimal sample size was calculated based on a previous study by Preis V. et al., (2013) (10) who investigated the two-body wear performance of monolithic dental ceramics with different surface treatments. By adopting a power of $80 \%$ to detect a standardized effect size in the percentage of wear (\%) $d=0.65$ (medium-sized standardized effect size), and level of significance $95 \% \quad(\alpha=0.05)$, the minimal required sample size was found to be 7 specimens per group (number of groups $=6$ ) (Total sample size $=7 \times 6=42$ specimens).

- This in vitro study included three groups :

- Group A ( $\mathrm{n}=7)$ : 7 enamel antagonists opposing 7 glazed ultra-translucent zirconia

- Group B ( $\mathrm{n}=7)$ : 7 enamel antagonists opposing 7 polished ultra-translucent zirconia

- Group C ( $\mathrm{n}=7)$ : 7 enamel antagonists opposing 7 enamel antagonists as a control group.

- Materials used in this study include (Table 1):

- Ultra-translucent zirconia, KATANA ${ }^{\text {TM }}$ Zirconia UTML.

- Intact human extracted maxillary pre-molars.

- Glaze material

- Polishing paste

Zirconia specimens' preparation

Fourteen discs were CAD/CAM (DWX-52D, Roland DGA Co, California, USA) milled from KATANA UTML with diameter of $12 \mathrm{~mm}$, and thickness $5 \mathrm{~mm}$. Then, sintered in a sintering furnace (Mihm-Vogt high temperature furnace, Mihm-Vogt Gmbh \& Co, Germany) at $1550^{\circ} \mathrm{C}$ for $2 \mathrm{~h}$ with a $10^{\circ} \mathrm{C} / \mathrm{min}$ heating and cooling rate according to the manufacturer's instructions. Seven discs were finished by a rubber wheel, and then, polished by polishing paste and polishing brush.

The other seven discs were glazed according to the manufacturer's instructions. They were polished, then sandblasted by alumina particles $(50 \sim 70 \mu \mathrm{m}, 30 \mathrm{psi}, 0.2 \mathrm{MPa})$, followed by ultrasonic cleaning (Shenzhen Codyson Electrical Co., Guangdong, China) for 10 minutes. Finally, a layer of clear glaze was applied and fired at a $600^{\circ} \mathrm{C}$ then left to cool at room temperature.

\section{Enamel antagonist preparation}

A total of twenty-eight intact, caries free human maxillary pre-molars extracted for orthodontic treatment were collected from the Oral Surgery Department at the Faculty of Dentistry, Alexandria. Previously restored teeth or teeth with surface defects as wear facets or cracks were excluded. The extracted teeth were thoroughly cleaned from any debris or calculus by ultrasonic scaler (P5 Neutron Acteon Satelec, Norwich, England) then disinfected in $0.2 \%$ sodium azide solution for 1 week and stored in distilled water (11). Buccal cusps were excised from the extracted teeth using a high speed handpiece (W \& $\mathrm{H}$ alegra handpiece, $\mathrm{W}$ \& $\mathrm{H}$
Dentalwerk, Burmoos, Austria) and a diamond coated bur (Horico diamond coated bur AUFG 199x016, 300.000 rpm, Germany) under copious irrigation. Followed by shortening and flattening the root portion using a diamond disc.

\section{Wear simulation}

Two-body wear test was conducted using a modified custom-made tooth brushing wear machine (Custom made tooth brushing machine, Dental Biomaterial Department, Alexandria University). The articulating component is formed of two parts: movable upper part and fixed lower part. The upper part consisted of four sliding bars. Each bar holds one single specimen with a weight can be placed on top of each bar. The fixed lower part formed of stainlesssteel base that can hold special fabricated specimen holder with two lateral fixing screws. The sliding arms move in antero-posterior direction, simulating the sliding movement during occlusal contacts in a chewing cycle. (Fig:1. A and Fig:1. B)

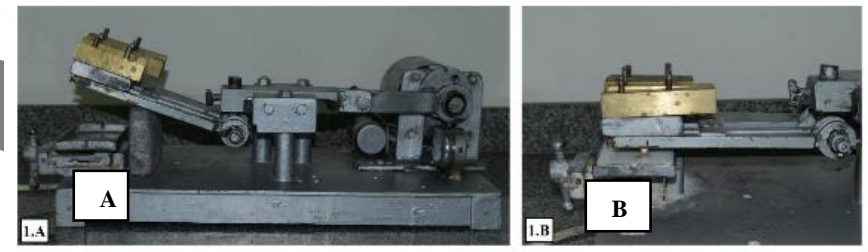

Fig. (1): A. Tooth brushing machine, B: Enamel antagonists and ceramic specimens fixed in the machine

A total number of 120,000 strokes with $5 \mathrm{Kg}$ equivalent to 49 $\mathrm{N}$ vertical load, $1 \mathrm{~Hz}$ frequency was applied $(12,13)$. Artificial saliva was prepared in the laboratory of faculty of pharmacy, Alexandria University (Table 1). It was continuously cycled over the specimens to resemble tooth lubrication during chewing in the oral cavity and to wash out the debris.

\section{Wear Assessment}

The quantitative assessment of the enamel antagonists wear was determined based on percentage of weight loss (14). All the enamel antagonists were weighed before and after the wear test using sensitive electronic balance with $0.0001 \mathrm{gm}$ accuracy (AS220.R2 Analytical balance, Radwag Balances and Scales, Bracka 28, 26-600 random, Poland). The amount of wear was calculated from the following equation: Wear (percent weight loss) $=$

Where: $\Delta \mathrm{W}=(\mathrm{W} 1-\mathrm{W} 2)$ difference in weight $(\mathrm{gm}), \mathrm{W} 1=$ Original weight of the specimen (gm), W2 =Weight of the specimen after wear (gm).

\section{Surface Roughness evaluation}

For surface roughness assessment, all the zirconia specimens and the enamel antagonists were scanned by the 3D laser scanning microscope (VK-X100 series, 3D laser scanning microscope, Keyence Inc.; Osaka, Japan). It provided a quantitative (Ra value) and qualitative analysis (2D picture) of the surface of the zirconia specimens and their teeth antagonists before and after chewing simulation.

\section{Data management and statistical analysis}

Normality was checked using descriptive statistics, and Kolmogorov-Smirnov test of normality. All variables showed normal distribution, so mean, and Standard Deviation (SD) were calculated. Comparing the studied 
groups was conducted using 1-way ANOVA test followed by post hoc test for multiple comparisons using GamesHowell method between the groups. Significance was set at $\mathrm{P}<0.05$. Data were analyzed using IBM SPSS statistical software (version 25).

\begin{tabular}{|c|c|c|c|}
\hline Material & Manufacturer & \multicolumn{2}{|c|}{ Composition } \\
\hline $\begin{array}{l}\text { Upper } \\
\text { translucent } \\
\text { zirconia UTML }\end{array}$ & $\begin{array}{c}\text { Kuraray Noritake } \\
\text { Dental, Tokyo, } \\
\text { Japan } \\
\end{array}$ & \multicolumn{2}{|c|}{$\begin{array}{l}\text { - Zirconium oxide } 87-92 \% \\
\text { - Yttrium oxide } 8 \text { - } 11 \% \\
\text { - Other oxide } 0 \text { - } 2 \%\end{array}$} \\
\hline $\begin{array}{l}\text { Cerabien ZR } \\
\text { Glaze }\end{array}$ & $\begin{array}{c}\text { Kuraray Noritake } \\
\text { Dental, Tokyo, } \\
\text { Japan }\end{array}$ & \multicolumn{2}{|c|}{$\begin{array}{l}\text { - Potassium alumino silicate } \\
\text { glass } \\
\text { - Pigments } \\
\text { - Glycerol } \\
\text { - 1,3-Butanediol }\end{array}$} \\
\hline Pearl surface $\mathrm{Z}$ & $\begin{array}{c}\text { Kuraray Noritake } \\
\text { Dental, Tokyo, } \\
\text { Japan } \\
\end{array}$ & \multicolumn{2}{|l|}{$\begin{array}{l}\text { - Quartz diamond } \\
\text { - Silicon Carbide } \\
\text { - Wax }\end{array}$} \\
\hline Pearl surface Z & $\begin{array}{c}\text { Kuraray Noritake } \\
\text { Dental, Tokyo, } \\
\text { Japan } \\
\end{array}$ & \multicolumn{2}{|l|}{$\begin{array}{l}\text { - Quartz diamond } \\
\text { - Silicon Carbide } \\
\text { - Wax }\end{array}$} \\
\hline \multirow[t]{8}{*}{ Artificial Saliva } & \multirow{8}{*}{$\begin{array}{c}\text { Faculty of Pharmacy, } \\
\text { Alexandria } \\
\text { University }\end{array}$} & Compound & $\begin{array}{l}\text { Conc. } \\
(\mathrm{gm} / \mathrm{L})\end{array}$ \\
\hline & & $\begin{array}{c}\mathrm{NaH}_{2} \mathrm{PO}_{4} \cdot 2 \mathrm{H}_{2} \\
\mathrm{O}\end{array}$ & \\
\hline & & $\mathrm{Na}_{2} \mathrm{~S} .9 \mathrm{H}_{2} \mathrm{C}$ & 0.005 \\
\hline & & $\mathrm{NaCl}$ & 0.4 \\
\hline & & $\mathrm{KCl}$ & 0.4 \\
\hline & & & 0.795 \\
\hline & & Urea & 1 \\
\hline & & $\mathrm{H}_{2} \mathrm{O}$ & $1 \mathrm{~L}$ \\
\hline
\end{tabular}

Table (1): Composition of materials used in the study

\section{RESULTS}

\section{Wear assessment}

The mean percentage weight loss of the opposing enamel antagonists is shown in (Table 2). The mean percentage weight loss of the enamel opposing enamel (control group) was $(5.335 \pm 0.324 \%)$ which higher than that of the enamel opposing the glazed UTMZ (3.932 $\pm 0.386 \%)$. Statistical comparison by Games-Howell method showed that the difference was statistically significant $\left(P<0.0001^{*}\right)$. Also, mean percentage weight loss of the enamel opposing enamel (control group) was higher than that of the enamel opposing the polished UTMZ $(3.286 \pm 0.588 \%)$. Statistical comparison by Games-Howell method showed that the difference between them was statistically significant $(P<$ $\left.0.0001^{*}\right)$.

Table (2): Percentage of weight loss after wear test between the enamel antagonists

\begin{tabular}{|c|c|c|c||}
\hline & $\begin{array}{c}\text { Enamel opposing } \\
\text { glazed UTMZ }\end{array}$ & $\begin{array}{c}\text { Enamel opposing } \\
\text { polished UTMZ }\end{array}$ & Control group \\
\hline $\begin{array}{c}\text { \% Weight Loss } \\
\text { Mean } \pm \text { SD }\end{array}$ & $3.932 \pm 0.386$ & $3.286 \pm 0.588$ & $5.335 \pm 0.324$ \\
Min-Max & $3.460-4.567$ & $2.470-4.228$ & $4.756-5.806$ \\
\hline $\begin{array}{c}\text { Test of } \\
\text { significance } \\
\text { P value }\end{array}$ & & $\mathrm{F}_{(\mathrm{d} f=2)}=64.386$ \\
$P<0.0001^{*}$ \\
\hline
\end{tabular}

Min-Max: Minimum - Maximum

SD: Standard Deviation

$\mathrm{df}=$ degree of freedom

*: Statistically significant $(\mathrm{p}<0.0001)$
The mean percentage weight loss of the enamel opposing the glazed UTMZ was higher than that of the enamel opposing the polished UTMZ. Statistical comparison by GamesHowell method showed that this difference was not statistically significant $(P>0.05)$ (Fig. 2).

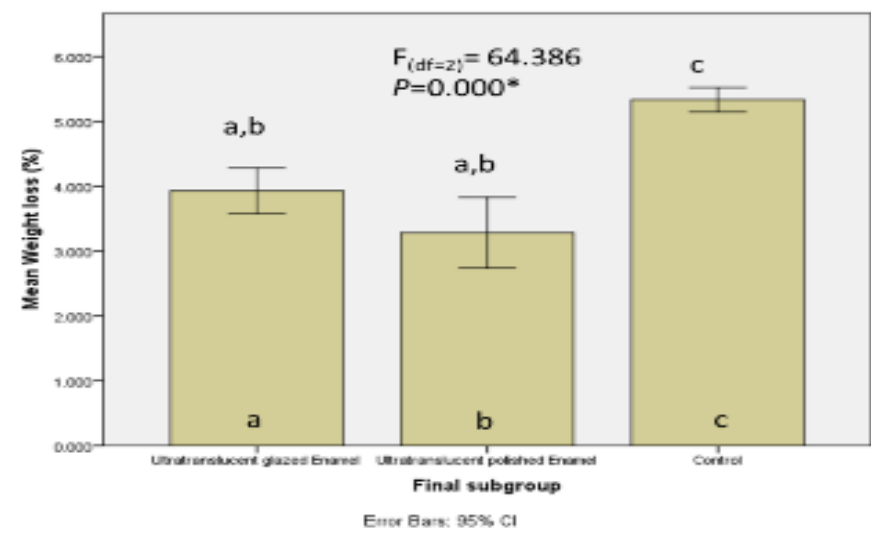

Fig. (2): Weight loss percentage of the enamel antagonists after wear test.

Different letters indicate pair-wise significance using Games-Howell method

\section{Surface roughness assessment}

The mean surface roughness of the zirconia specimens and the enamel antagonists before and after the wear test is shown in (Table 3).

The mean surface roughness values of glazed UTMZ specimens were $(1.479 \pm 0.324 \mu \mathrm{m})$ before wear test, and $(1.903 \pm 0.281 \mu \mathrm{m})$ after wear test, while their antagonist enamel mean surface roughness values were $(1.504 \pm 0.239 \mu \mathrm{m})$ before test, and $(2.872 \pm 0.114 \mu \mathrm{m})$ after wear.

Table (3): The mean surface roughness and Surface roughness percentage of change of the studied groups before and after the wear test

\begin{tabular}{|c|c|c|c|c|c|}
\hline & $\begin{array}{l}\text { Surface } \\
\text { Roughne } \\
\text { ss before } \\
\text { wear test } \\
\end{array}$ & $\begin{array}{c}\text { Surface } \\
\text { Roughness } \\
\text { after wear } \\
\text { test } \\
\end{array}$ & $\begin{array}{l}\text { Test of } \\
\text { significanc } \\
\text { e } p \text { value }\end{array}$ & $\begin{array}{l}\% \text { of change } \\
\text { in surface } \\
\text { roughness }\end{array}$ & $\begin{array}{c}\text { Test of } \\
\text { signific } \\
\text { ance } \\
p \text { value } \\
\end{array}$ \\
\hline $\begin{array}{l}\text { Glazed UTMZ } \\
\text { Specimens } \\
\text { Mean } \pm \text { SD } \\
\text { Min-Max }\end{array}$ & $\begin{array}{r}1.479 \pm 0.324 \\
1.000-1.950\end{array}$ & $\begin{array}{l}1.903 \pm 0.281 \\
1.448-2.236\end{array}$ & $\begin{array}{c}\mathrm{t}=10.542 \\
P<0.0001^{*}\end{array}$ & $\begin{array}{l}30.580 \pm 11.230 \\
14.667-44.800\end{array}$ & \multirow{5}{*}{$\begin{array}{c}F_{(\mathrm{df}=4)} \\
=34.766 \\
P<0.0001\end{array}$} \\
\hline $\begin{array}{l}\text { Enamel } \\
\text { opposing } \\
\text { glazed UTMZ } \\
\text { Mean } \pm \text { SD } \\
\text { Min-Max }\end{array}$ & \begin{tabular}{|l|}
$1.504 \pm 0.239$ \\
$1.215-1.900$
\end{tabular} & $\begin{array}{l}2.872 \pm 0.114 \\
2.722-2.996\end{array}$ & $\begin{array}{c}\mathrm{t}=11.643 \\
P<0.0001^{*}\end{array}$ & $\begin{array}{c}95.296 \pm 32.457 \\
43.263-136.132\end{array}$ & \\
\hline $\begin{array}{l}\text { Polished } \\
\text { UTMZ } \\
\text { specimens } \\
\text { Mean } \pm \text { SD } \\
\text { Min-Max }\end{array}$ & $\begin{array}{l}1.459 \pm 0.317 \\
1.098-1.950\end{array}$ & $\begin{array}{l}1.802 \pm 0.259 \\
1.545-2.265\end{array}$ & $\begin{array}{c}\mathrm{t}=9.402 \\
P<0.0001^{*}\end{array}$ & $\begin{array}{l}25.390 \pm 11.652 \\
13.029-41.595\end{array}$ & \\
\hline 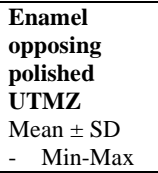 & $\begin{array}{l}1.602 \pm 0.270 \\
1.226-1.900\end{array}$ & $\begin{array}{l}2.462 \pm 0.183 \\
2.218-2.653\end{array}$ & $\begin{array}{c}\mathrm{t}=6.559 \\
P<0.0001 *\end{array}$ & $\begin{array}{r}58.028 \pm 32.760 \\
25.579-114.274\end{array}$ & \\
\hline $\begin{array}{l}\text { Control group } \\
\text { Mean } \pm \text { SD } \\
-\quad \text { Min-Max } \\
\end{array}$ & \begin{tabular}{|l|} 
\\
$1.563 \pm 0.233$ \\
$1.035-1.900$
\end{tabular} & $\begin{array}{l}4.702 \pm 0.396 \\
4.056-5.338 \\
\end{array}$ & $\begin{array}{c}\mathrm{t}=25.514 \\
P<0.0001^{*}\end{array}$ & $\begin{array}{r}208.378 \pm 63.170 \\
135.833-388.116 \\
\end{array}$ & \\
\hline
\end{tabular}


The mean surface roughness values of polished UTMZ specimens were $(1.459 \pm 0.317 \mu \mathrm{m})$ before wear test, and $(1.802 \pm 0.259 \mu \mathrm{m})$ after wear test, and their enamel antagonist mean surface roughness were $(1.602 \pm 0.270 \mu \mathrm{m})$ before test, and $(2.462 \pm 0.183 \mu \mathrm{m})$ after wear.

As for the control group, before the wear test the mean surface roughness was $(1.563 \pm 0.233 \mu \mathrm{m})$, and after the wear test was $(4.702 \pm 0.396 \mu \mathrm{m})$.

Statistical comparison between the studied groups before and after wear test by applying paired t test showed that there was a significant increase in the surface roughness $(P<$ 0.0001*). (Fig. 3)

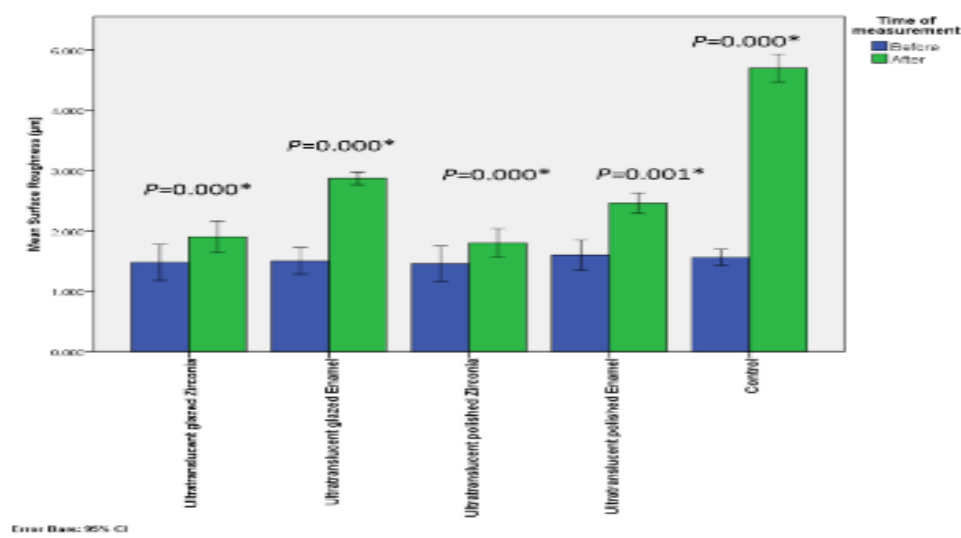

Fig. (3): Mean surface roughness of zirconia specimens and enamel antagonists before and after wear test.

Percentage of change in surface roughness of zirconia and enamel specimens after wear test

After the wear simulation the mean percentage of change in the surface roughness of the enamel opposing enamel (control group) was (208.378 $\pm 63.170 \%)$ which was higher than that of the enamel opposing glazed UTMZ (95.296 \pm $32.457 \%$ ). Statistical comparison by Games-Howell method showed that there was a statistically significant difference between them $\left(P<0.0001^{*}\right)$.

The mean percentage of change in the surface roughness of the enamel opposing enamel (control group) was also higher than that of the enamel opposing polished UTMZ (58.028 \pm $32.760 \%$ ). Statistical comparison by Games-Howell method showed that there was a statistically significant difference between them $\left(\mathrm{P}<0.0001^{*}\right)$.

The mean percentage of change in surface roughness of ultra-translucent glazed zirconia specimens was $(30.580 \pm 11.230 \%)$, and their enamel antagonists was (95.296 $\pm 32.457 \%)$. Statistical comparison by GamesHowell method showed that there was a statistically significant difference between them $(\mathrm{P}<0.0001 *)$.

While the mean percentage of change in surface roughness of the ultra-translucent polished zirconia specimens was $(25.390 \pm 11.652 \%)$, and their enamel antagonists was $(58.028 \pm 32.760 \%)$. Statistical comparison by Games-Howell method showed that there was no statistically significant difference between them $(P>0.05)$. (Table 3) (Fig. 4)

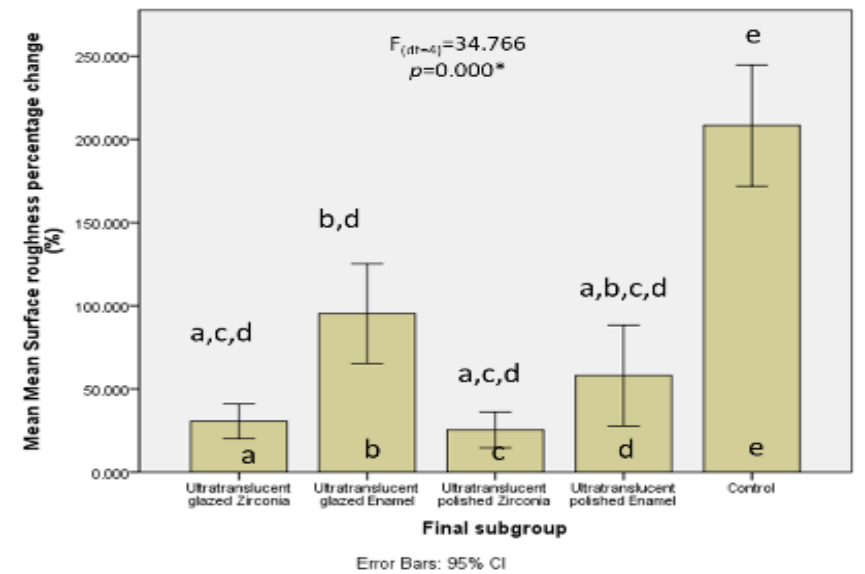

Fig. (4): Surface roughness percentage of change of the zirconia specimens and enamel antagonists after wear test.

Different letters indicate pair-wise significance using Games-Howell method

\section{Surface topography}

Zirconia and enamel specimens were analyzed using 3D laser microscope to provide $2 \mathrm{D}$ pictures. After the wear simulation, polished UTMZ discs showed narrow, shallow and smooth wear scratches (Fig. 5.A). While glazed UTMZ discs showed chipping of parts of the glaze layer along the wear path of the antagonist enamel cusp (Fig.5.B). The enamel antagonists of polished UTMZ showed a relatively smooth surface with very shallow and superficial wear traces (Fig.5.C). While the enamel antagonists of the glazed UTMZ showed a rougher surface with slightly deeper wear striations (Fig. 5. D). The enamel antagonists of the control group exhibited the steepest sliding grooves in the wear facets. (Fig.6.A) One of the enamel antagonists of the control group showed micro crack under the microscope (Fig 6.B).

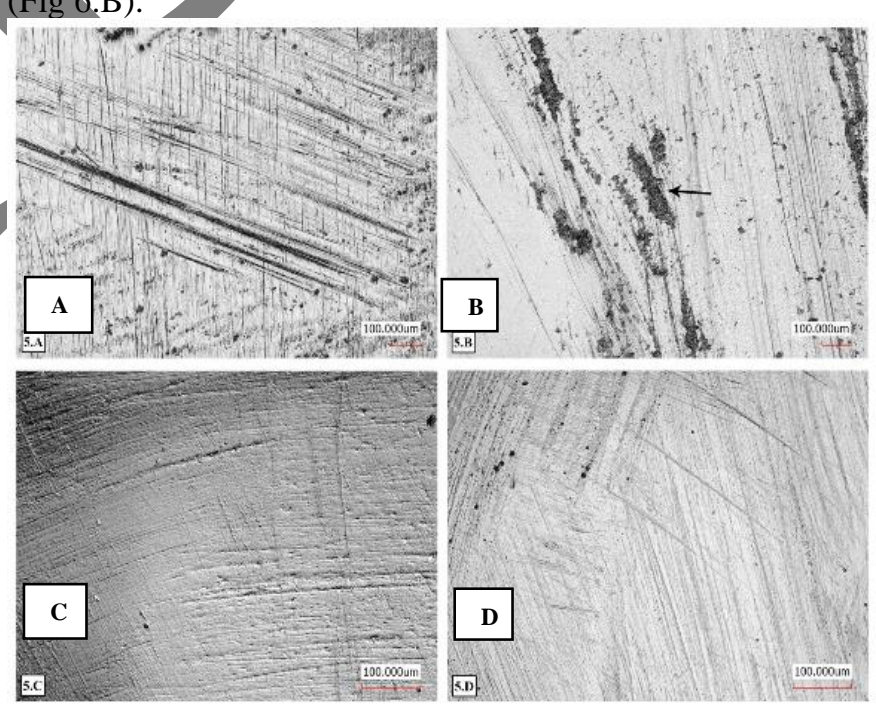

Fig. (5): 2D images after wear test: A: Polished UTMZ, B: Glazed UTMZ, C: Enamel opposing polished UTMZ, D: Enamel opposing glazed UTMZ. 


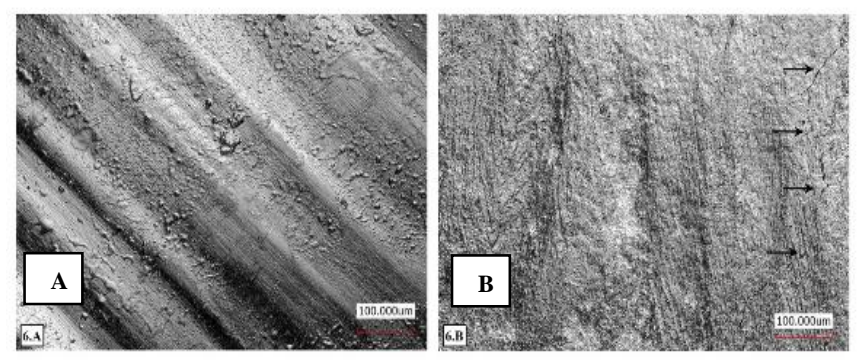

Fig. (6): 2D images after wear test of Enamel antagonist of control group,A: showing deeper sliding grooves, B: showing microcracks

\section{DISCUSSION}

This study was an attempt to investigate the enamel wear behavior opposing glazed and polished ultra-translucent zirconia. There were huge variations in literature regarding the wear test device designs, and the parameters. Therefore, in this study, testing conditions were chosen to be close to the clinical situation. A total of 120,000 cycle was applied equivalent to 6 months of clinical chewing cycle. (15) Vertical load of $49 \mathrm{~N}$ equivalent to $5 \mathrm{~kg}$ was applied which is considered as average value for physiological masticatory forces in the teeth of non-bruxism patients (16-18).

From the given results of the current study, polished UTMZ yielded significantly less enamel antagonist wear than the glazed UTMZ and the natural enamel. This could be due to the polycrystalline structure of the polished UTMZ that makes it well packed, dense microstructure with no voids. This ensures a smooth surface throughout the wear process resulting in limited wear to the antagonist enamel. This coincides with Kwon et al., (19) found that the polished UTMZ caused lower antagonist wear than the natural enamel.

The fact that the glazed UTMZ led to more antagonist wear than the UTMZ could be attributed to the brittle nature and insufficient toughness of the glaze layer which is mainly silica and quartz. This led to chipping in superficial glaze layer exposing the rough sharp glass particles. These particles behave as an abrasive medium and roughen the opposing enamel starting a cycle of abrasive wear. This is in agreement with Janyavula et al., (20) who reported that the glazed anatomically contoured zirconia exhibited more antagonist wear than the polished anatomically contoured zirconia. They explained that the worn-out particles from the glaze may act as a third body abrasive material. Also, Park et al., (21) reported more antagonist wear with the glazed than the polished monolithic zirconia. They attributed this to the disappearance of the thin glaze layer during mastication exposing the rough zirconia substructure. This observation is also consistent with Sabrah et al., (22) who stated that although the glazed zirconia offered a primary smooth surface, yet it significantly led to more hydroxyapatite antagonist wear than the polished zirconia.

The current results showed that the natural enamel control group caused the highest wear to the opposing antagonist teeth. This could be attributed to that the chipped hydroxyapatite particles acted as an abrasive medium causing three body wear cycle. This is in agreement with
Zheng et al., (23) who reported that the delamination of the enamel resulted in wear particles that acted as a wear medium. This also coincides with Sripetchdanond et al., (24) who found that the natural enamel caused significantly more wear to the antagonist than the monolithic zirconia.

Concerning surface roughness, the natural enamel of the control group showed significantly higher surface roughness after the wear test than the enamel opposing ultra-translucent glazed zirconia and the enamel opposing ultra-translucent polished zirconia. Chong et al., (25) suggested that the pitting on the enamel opposing enamel after wear was due to the chipping of enamel prisms from the rough enamel surfaces abrading each other. Also, Preis et al., (10) reported higher surface roughness of the enamel than the polished and glazed monolithic zirconia.

The percentage of surface roughness change of the natural enamel of the control group increased the double (208.379 \pm $63.170 \%$ ), while the enamel opposing the glazed ultratranslucent zirconia increased by almost one fold (95.296 \pm $32.457 \%$ ), and the enamel opposing the polished ultratranslucent zirconia increased only by (58.028 $\pm 63.179 \%)$. It could be explained as the wear simulation process begins, enamel loss occurs, followed by an increase in the surface roughness of the antagonist enamel. High surface roughness will increase the friction at the interface and have a higher abrasive action on the antagonist wear. This is in agreement with the amount weight loss stated previously. This coincides with Elmaria et al., (26) who reported a significant correlation between the surface roughness and the enamel wear.

Our results showed that polishing the UTMZ resulted in the less antagonist enamel wear and surface roughness than the glazed UTMZ, Therefore, the finishing procedure of the UTMZ affected the antagonist enamel wear and surface roughness in comparison to natural opposing enamel. Thus, the null hypotheses were rejected.

\section{CONCLUSIONS}

Within the limitation of this study,

1- Polished UTMZ can be used as an alternative to glazed UTMZ restorations in high load bearing areas to minimize the antagonist enamel wear.

2- Both polished and glazed UTMZ showed lower surface roughness after wear simulation compared to that of the natural enamel.

3- Any increase in the surface roughness leads to an increase in the antagonist wear.

\section{Recommendations}

1. Future studies may examine the wear produced from high occlusal forces such as the maximum limits of mastication or parafunctional habit forces (bruxing).

2. For conclusive evidence of the acceptability of this new fully stabilized translucent zirconia, controlled clinical trials which measure opposing enamel wear must be conducted.

\section{CONFLICT OF INTEREST}

The authors declare that they have no conflicts of interest. 


\section{REFERENCES}

1. Kelly JR, Benetti P. Ceramic materials in dentistry: historical evolution and current practice. Aust Dent J. 2011;56:84-96.

2. Miyazaki T, Nakamura $\mathrm{T}$, Matsumura $\mathrm{H}$, Ban $\mathrm{S}$, Kobayashi T. Current status of zirconia restoration. J Prosthodont Res. 2013;57:236-61.

3. Manicone PF, Iommetti PR, Raffaelli L. An overview of zirconia ceramics: basic properties and clinical applications. J Dent. 2007;35:819-26.

4. Jang G, Kim H, Choe H, Son M. Fracture strength and mechanism of dental ceramic crown with zirconia thickness. Procedia Eng. 2011;10:1556-60.

5. Baldissara P, Wandscher VF, Marchionatti AME, Parisi C, Monaco C, Ciocca L. Translucency of IPS e. max and cubic zirconia monolithic crowns. J Prosthet Dent. 2018;120:269-75.

6. Yip KH, Smales RJ, Kaidonis JA. Differential wear of teeth and restorative materials: Clinical implications. Int J Prosthodont. 2004;17:350-6.

7. D'Arcangelo C, Vanini L, Rondoni GD, De Angelis F. Wear properties of dental ceramics and porcelains compared with human enamel. J Prosthet Dent. 2016;115:350-5.

8. Mundhe K, Jain V, Pruthi G, Shah N. Clinical study to evaluate the wear of natural enamel antagonist to zirconia and metal ceramic crowns. J Prosthet Dent. 2015;114:358-63.

9. DeLong R. Intra-oral restorative materials wear: rethinking the current approaches: how to measure wear. Dent Mater. 2006;22:702-11.

10. Preis V, Weiser F, Handel G, Rosentritt M. Wear performance of monolithic dental ceramics with different surface treatments. Quintessence Int. 2013;44:393-405.

11. Heintze SD, Cavalleri A, Forjanic M, Zellweger G, Rousson V. Wear of ceramic and antagonist--a systematic evaluation of influencing factors in vitro. Dent Mater. 2008;24:433-49.

12. Preis V, Behr M, Handel G, Schneider-Feyrer S, Hahnel $\mathrm{S}$, Rosentritt M. Wear performance of dental ceramics after grinding and polishing treatments. J Mech Behay Biomed Mater. 2012;10:13-22.

13. Rosentritt M, Preis V, Behr M, Hahnel S, Handel G, Kolbeck C. Two-body wear of dental porcelain and substructure oxide ceramics. Clin Oral Investig. 2012;16:935-43.
14. Wang L, Garcia FC, Amarante de Araújo P, Franco EB, Mondelli RF. Wear Resistance of Packable Resin Composites after Simulated Toothbrushing Test. J Esthet Restor Dent. 2004;16:303-14.

15. Krejci I, Albert P, Lutz F. The influence of antagonist standardization on wear. J Dent Res. 1999;78:713-9.

16. Gibbs CH, Mahan PE, Lundeen HC, Brehnan K, Walsh EK, Sinkewiz SL, et al. Occlusal forces during chewinginfluences of biting strength and food consistency. J Prosthet Dent. 1981;46:561-7.

17. Kunzelmann KH. Verschleissanalyse undquantifizierung von Füllungsmaterialien in vivo und in vitro. Aachen: Shaker; 1998.

18. Rosentritt M, Behr M, van der Zel JM, Feilzer AJ. Approach for valuating the influence of laboratory simulation. Dent Mater. 2009;25:348-52.

19. Kwon SJ, Lawson NC, McLaren EE, Nejat AH, Burgess JO. Comparison of the mechanical properties of translucent zirconia and lithium disilicate. J Prosthet Dent. 2018;120:132-7

20. Janyavula S, Lawson N, Cakir D, Beck P, Ramp LC, Burgess JO. The wear of polished and glazed zirconia against enamel. J Prosthet Dent. 2013;109:22-9.

21. Park JH, Park S, Lee K, Yun KD, Lim HP. Antagonist wear of three CAD/CAM anatomic contour zirconia ceramics. J Prosthet Dent. 2014;111:20-9.

22. Sabrah AH, Cook NB, Luangruangrong P, Hara AT, Bottino MC. Full-contour Y-TZP ceramic surface roughness effect on synthetic hydroxyapatite wear. Dent Mater. 2013;29:666-73.

23. Zheng J, Zeng Y, Wen J, Zheng L, Zhou Z. Impact wear behavior of human tooth enamel under simulated chewing conditions. J Mech Behav Biomed Mater. 2016;62:119-27.

24. Sripetchdanond J, Leevailoj C. Wear of human enamel opposing monolithic zirconia, glass ceramic, and composite resin. an in vitro study. J Prosthet Dent. 2014;112:1141-50.

25. Chong BJ, Thangavel AK, Rolton SB, Guazzato M, Klineberg IJ. Clinical and laboratory surface finishing procedures for zirconia on opposing human enamel wear: A laboratory study. J Mech Behav Biomed Mater. 2015;50:93-103.

26. Elmaria A, Goldstein G, Vijayaraghavan T, Legeros RZ, Hittelman EL. An evaluation of wear when enamel is opposed by various ceramic materials and gold. J Prosthet Dent. 2006;96:345-53. 